\title{
Patent Investigation on Pellet Biomass from Empty Fruit Bunch to Enhance Innovation Development of Renewable Energy
}

\author{
Tommy Hendrix, Adityo Wicaksono, Firman Tri Ajie \\ Pusat Inovasi Lembaga Ilmu Pengetahuan Indonesia \\ Bogor, Indonesia \\ tommy.hendrix@lipi.go.id
}

\begin{abstract}
Sustainability of renewable energy development has become big issue. Government has set its target to replace fossil fuel based energy into new and renewable energy. For this, research and development $(\mathrm{RnD})$ in renewable energy sector must be massively done and should be well planned. On the contrary, many research institutions conducting $\mathrm{RnD}$ without clear direction and many of them are overlapping. Patent investigation can be a solution for this problem, it able to unravel hidden patterns and trends in what researcher invented globally. This research is specifically aim to see the trend in Empty Fruit Bunch (EFB) biomass pellet $\mathrm{RnD}$ and give innovation stakeholder a better perspective towards the enhancement of renewable energy development. This research used qualitative method with desciptive analysis. Literature review was conducted using Matheo Patent XE Ver.10.2 software. As a result is to find the development of technology and products that have been produced as well as commercial processes connecting with technology users, especially in pellet biomass. Summary of this paper is objective to see the differences on significance innovation development on pellet biomass from EFB to enhance utilization palm tree in source energy preservation.
\end{abstract}

Keyword: Empty Fruit Bunch, Innovation, Patent Investigation, Pellet Biomass, Renewable Energy

\section{INTRODUCTION}

Patent is one of intellectual property branch that protect inventions as output for research and development activities. Worldwide patent performance has rose significantly from 2010 until now, it can be shown on many request from stakeholder to use patent as a tool to lift up performance of their products. Entering the new millennium, intellectual property becomes a very important issue that always gets the attention both in national and international forum, the inclusion of TRIPs in the package of WTO Agreement in 1994 marked the start of a new era of the development of intellectual property throughout the world. Thus at present the problem of intellectual property cannot be released from world trade and investment. The importance of intellectual property in economic development and trade has spurred the start of a new era of economic development based on Science. Among other things, guarantees the protection of the moral and economic interests of the owner. The development of intellectual property systems have been directed to be guiding fences, and simultaneously signs for industrial activity and trade traffic. Macroeconomic scale, intellectual property right designed to energize and motivate the community to better able to move the entire economic potential and supported by many policy for implementation especially in lifting the awareness of stakeholder on importance to set up protection in their activities.

In this papers, patent investigation mean that we search, combine, analyze and interpretation some of database that can be used as a tool in managing technology transfer especially from research and development result. Meanwhile the critical of utilization on that system must be clarified through some innovation step that enhance capability to produce information that useful for stakeholder. Despite the widely shared view that technological knowledge is one of the most important factors in economic development, many difficulties have been encountered in the measurement and counting of technological knowledge. The sources of data capable of serving as a basis for studying technological knowledge have been limited, stemming from the difficulties inherent in measuring knowledge. Patent data has been considered one of the few precious sources of standardized information for technological knowledge [1].

If we talk about energy now, we heard that supplies fuel oil on earth is thinning. There are many estimates by experts that supply of fuel oil per years will be completely depleted. While to update the oil contained in the earth, nor is it easy and instant. So, inevitably the humans are forced to continue to find alternatives energy of fuel oil. The prospect of producing clean, sustainable power in substantial quantities from biomass in the form of agricultural residues is now arousing interest worldwide, stimulated by increasing concern over the environmental consequences of conventional fossil and nuclear fuel use [2]. One of the alternative energy that can be developed is biomass energy. The reason for that statement is, with our rich potential natural resources in Indonesia can be basic capital for generating the new source of energy. Indonesia has faced to the problem of energy crisis, especially oil price crisis, has been relying on fossil fuel as the primary source of energy and simultaneously Indonesia energy consumption has been increased rapidly and continuously. The 
development of innovation that have been work it in field of pellet biomass from empty fruit bunch is biological waste from processing of palm oil. Waste material becomes a big problem for oil processing plant because of the volume and the costs involved. Bunches of fibers are blank produced from Processing Technology Blank Bunch has many uses. This biomass material can be used to produce energy, compost, mulch, making pellets, etc. This uses become so important to reduce the limitations of electric energy, if we can capitalized into the new form of energy substitution based non fossil resources.

\section{TABLE I. THE Potency OF BIOMASS FOR ElECTRICITy [3]}

\begin{tabular}{|l|l|r|r|r|r|r|r|r|r|r|}
\hline No. $\begin{array}{c}\text { General Potency } \\
\text { (Mwe) }\end{array}$ & Unit & Sumatera & Kalimantan & $\begin{array}{c}\text { Java-Bali- } \\
\text { Madura }\end{array}$ & Nusa Tenggara & Sulawesi & Molucas & Papua & Total \\
\hline 1 Palm Oil & Mwe & 8,812 & 3,384 & 60 & - & 323 & - & 75 & 12,654 \\
\hline 2 & Sugar Cane & Mwe & 399 & - & 854 & - & 42 & - & - & 1,295 \\
\hline 3 & Rubber & Mwe & 1,918 & 862 & - & - & - & - & - & 2,780 \\
\hline 4 & Coconut & Mwe & 53 & 10 & 37 & 7 & 38 & 19 & 14 & 178 \\
\hline 5 & Rice Paddy & Mwe & 2,255 & 642 & 5,353 & 405 & 1,111 & 22 & 20 & 9,808 \\
\hline 6 & Corn & Mwe & 408 & 30 & 954 & 85 & 251 & 4 & 1 & 1,733 \\
\hline 7 Cassava & Mwe & 110 & 7 & 120 & 18 & 12 & 2 & 1 & 270 \\
\hline 8 Wood & Mwe & 1,212 & 44 & 14 & 19 & 21 & 4 & 21 & 1,335 \\
\hline 9 & Livestock(cattle) & Mwe & 96 & 16 & 296 & 53 & 65 & 5 & 4 & 535 \\
\hline 10 & Solid waste & Mwe & 326 & 66 & 1,527 & 48 & 74 & 11 & 14 & 2,066 \\
\hline & Total General & Mwe & 15,589 & 5,061 & 9,215 & 635 & 1,937 & 67 & 150 & 32,654 \\
\hline & Potency & & & & & & & & \\
\hline
\end{tabular}

This research used qualitative method with desciptive analysis. Literature review was conducted using Matheo Patent XE Ver.10.2 software to get a comprehensive patent nature related to EFB biomass pellet. This software is able to do data mining and analysis using patent database that registered within 2007 until 2016 worldwide. Hidden patterns and certain trends can be unravel by using data mining and analysis [4]. This is the core of patent investigation that can give a better perspective for researcher or policy maker in Indonesia to determine $\mathrm{RnD}$ direction related to $\mathrm{EFB}$ biomass pellet to enhance the development of renewable energy.

\section{Matheo Patent as A Technology Foresight to ENHANCE INFORMATION PELLET BIOMASS FROM EFB}

Development on using patent as database of source technology, become big issue to discuss and can lift up many potential benefit from market demand especially from product diversification. Patent as a supporting program that can be the source of R \& D result, especially in part of process technology transfer and licensing become IPRs will bring up a fairly difficult problem, in which developing countries generally requires IP owners to grant the license transfer technology that enables the guarantee for holders of such licenses to be able to replicate the technology. This has spurred empowerment of $\mathrm{R}$ \& D results that can be used by the license in the form of technology transfer especially in using patent as intangible asset based on R \& D activities [5]. In comparison with other information sources, patents are often considered to be the best source for the timely recognition of technological changes [6]. $t$ is assumed that technological fields with high relative patent growth rates will be more attractive in the future than those fields with low relative patent growth. Empirical studies show a positive and lagged relationship between patent growth and competitive changes in the market [7].

One of tool can be use and provide many information related to subject that want to be find by using searching patent document with software Matheo Patent XE Ver. 10.2, this result more useful to determine potentials useful through strategy, research and development, patent analysis and patent collaboration among users. The result from patent document referable to trace the development of the technology, the important in patent documents there is prior art which is a technology earlier. Any technology that contained in patent documents have a novelty and the advantages of technology than its predecessor. It could be the keys to see the differences on methodologies and system that contain valuable information on patent application and specific confidentiality. The data comprises: total of patent data and patent families, review of the content/focus of the patent. Categories of ingredients are grouped according to the contents stated in "claims" of the patent document, country of inventors, countries where the patent is registered (country of applicants), the main industries and applicants involved.

Besides of that also used WIPO database as supporting reference for data mining as a benchmarking possibilities of useful patent that use as free tool. Figure 1. Show the common usefulness of patent searching activities to enhance the meaningful of utilization appropriate technology.

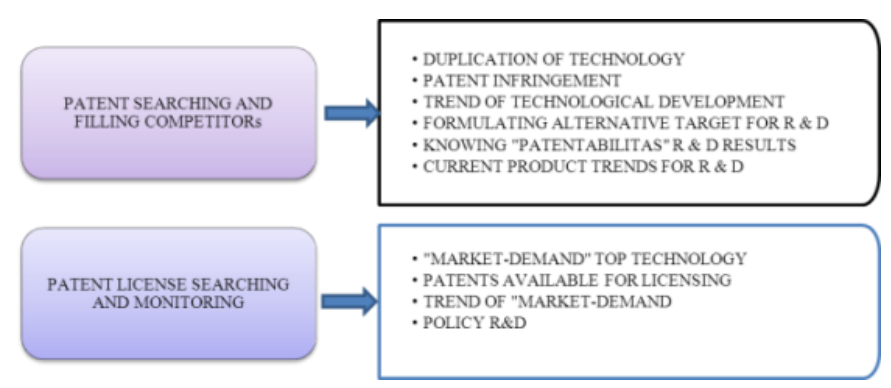

Fig. 1. Usefullness of Patent Searching

In case of this papers, used keyword pellet biomass and empty fruit bunch for starting to seek document related to development of renewable resources. This method necessary in order to measure the level of development of the utilization materials of pellet biomass, with primarily existing data through patent search possibilities of utilization can be seen widely in the productive efforts and potential, so the fulfillment of renewable energy needs can be clarified based on existing uses especially product from empty fruit bunch to pellet biomass.

\section{INNOVATION DEVELOPMENT OF RENEWABLE ENERGY}

Palm oil industry in Indonesia from year to year increases significantly. The price of palm oil in the international market also tends to improve. This led to the palm oil industry can become a mainstay of foreign exchange in the future. Figure 
2., define model LEAP (Long-range Energy Alternatives Planning System) of energy conservation that combine analysis of the energy consumption, transformation, and the production of energy in a system by using the indicators between Another indicator of demographics, economic development, technology, pricing, policies, and regulations [8].

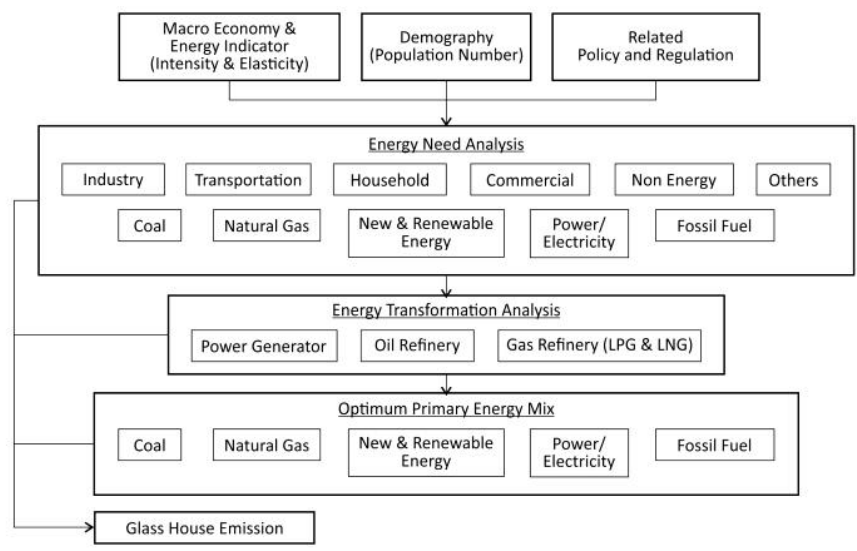

Fig. 2. Long-range Energy Alternatives Planning System of energy conservation

The capacity development in renewable energy nowadays in Indonesia refer to Regulation No. 5/2006 about National energy policy. In the Regulation mentioned the contribution of renewable energy in the national primary energy mix until 2025 is $17 \%$ with a composition of Biofuels of $5 \%$, geothermal, Biomass, nuclear, hydro, solar, and wind is $5 \%$, and coal were disbursed amounted to $2 \%$. For that the steps to be taken the Government is adding to the installed capacity of Micro Hydro power plants be $2.846 \mathrm{MW}$ by 2025 , installed capacity $180 \mathrm{MW}$ Biomass by 2020, the installed capacity of wind 0.97 of GW by 2025, Solar $0.87 \mathrm{GW}$ by the year 2024, and 4.2 Nuclear GW in the year 2024. Total investment absorbed renewable energy development until 2025 is projected of 13.197 million USD. From that description it seem the utilization of non fossil can be lift up more that number that occurs above. Biomass is promoted as an alternative to a very promising in the utilization of renewable energy certainly has some advantages when used wisely and effectively in the industry especially utilization of empty fruit bunch. Biomass is organic matter that is the result of activities photosynthesis either products or exile. Biomass and reports can be used as one source of alternative energy. Problems encountered is how to improve the utilization of the waste so as to more efficiently and provide high economic value, of course it takes enough knowledge about the technology and the wisdom to use it. Empty fruit bunch has great potential to become a source of cellulosic biomass with high enough abundance and its renewable, product from the processing of palm oil that it is used as a fertilizer is still limited, and media for growth fungi and plants. EFB is the solid wastes from palm oil industries which can be found abundantly in Asian countries like Malaysia, Indonesia, Thailand and tropical African country [9]. Waste oil palm the number is very abundant, any processing 1 Ton will be generated EFB equal as $23 \%$ or as much as $230 \mathrm{Kg}$ EFB.

We must ready to face the challenge of energy development become big issue in energy preservation. All of problem and barriers must be faced directly to proportion of our energy needs, especially in utilization from natural resources in Indonesia as shown in figure 3.

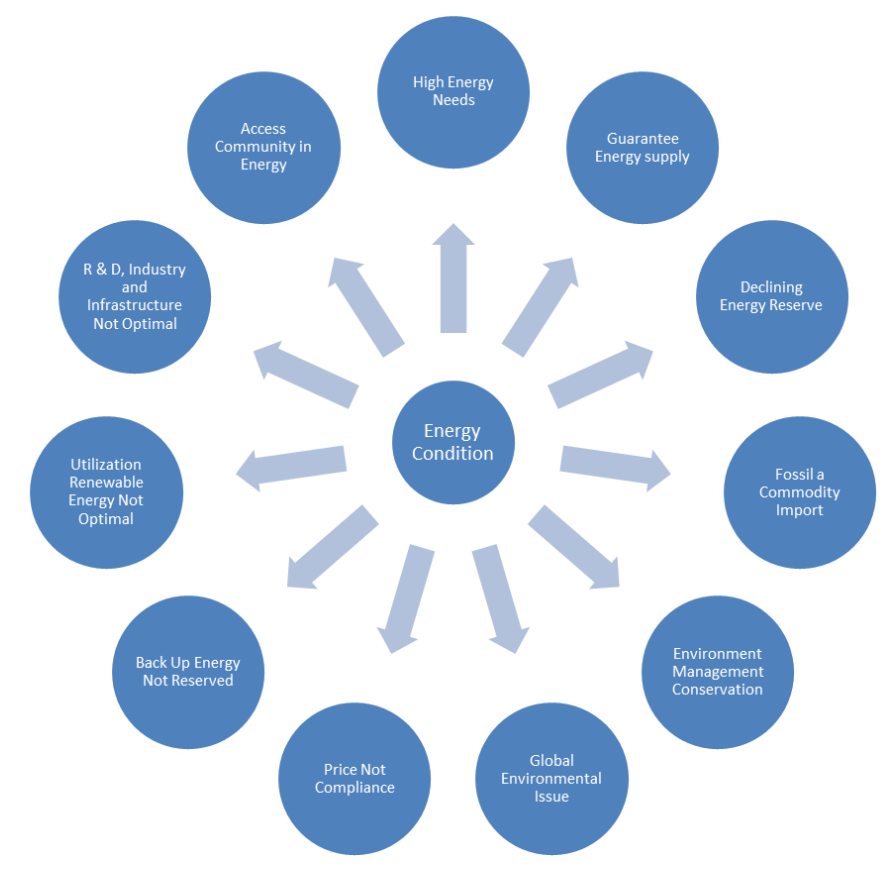

Fig. 3. Energy Condition in Indonesia [4]

The concept of zero emissions is the concept that implements systems that industrial processes should not generate waste in any form because of the waste can be used as raw materials for other industries. Through the process of applying the concept of the industrial processes saves natural resources, expand the types of products, creating more jobs and prevent pollution and environmental damage. With innovation process that description above can be tool to deliberating many source of technology may acquisition the needs of industries requirement. So to enhance many capacity of useful in empty fruit bunch, need information regarding the population of technology that can bear more specific requirement in the market especially from product that produce by utilization of waste empty fruit bunch.

One that we can discuss in this papers through patent investigation to see more variation of technology that can be apply for overcome the crisis of energy in Indonesia. This method may interact many stakeholder can be cooperate in utilized potential markets that need to be observed. The result of data patent that used is valid give us opportunity collaborate to enhance innovation technology for renewable energy portion in Indonesia. Including the utilization the results of research and development could have been registered by other 
parties who are legally able to hold the patent rights so that the other party including those of us who find it must pay a royalty to the patent holder [10]. It's mean we have benefit of doing the protection intellectual property from data patent through technology in general are :

1. Exclusive rights is against the results of the discovery;

2. Give a stronger position because more legal;

3. Reduce competition in other parties to utilize the results of discovery;

4. Higher Return of Investment (ROI);

5. Licensing opportunities are greater because investors are more interested;

6. Improve the bargaining position of product or technology;

7. Give a positive image for the company license holders.

At least there are three aspects that can be a reference in the election strategy of intellectual property protection. Aspects of time use (technological advancement, advancement of technology alternatives, market acceptance); aspects of power competition (quality, cost efficiency, reliability, flexibility) aspects and advantages and benefits (mastery of prospective market areas, market size, market needs and benefits of infestations, the determination of price and investment return period) [11].

\section{THE RESULT PATENT SERACHING FROM PELLET BIOMASS AND EMPTY FRUIT BUNCH}

Based on patent data search results, indicating that a large number of which have been exploited on the basis of biomass pellets from oil palm bunches as much patent family with a total 107 and 58 patent. With the range of data that is traced over 10 years from 2007 - 2016. Description of all patent information can be display on Figure 4.

By using keyword pellet biomass and empty fruit bunch, description patent shown that Method 34, Xylitol Production 4, Agricultural Biomass 3 and Fuel Pellet Comprising 3, has a large number in implementation. It's mean that urgencies on application can deliver many fields of information related technology of process can be used from registration of international patent. Methods used to produce certain products, and test the effectiveness of a particular product. Its concerns the way of working to be able to understand the science of the target object in concerned. The function of the method means as a means to achieve a goal, or how to do or make something related to subject of research that will be done. Xylitol Production was the reduced sugar or xylitol polyols have a sweetness same as sucrose, so xylitol can be used instead of sugar in the food processing industry. All of this utilized by the food and beverage industry. Agricultural biomass is a relatively broad category of biomass that includes: the food-based portion of crops (such as corn, sugarcane, and beets), the nonfood-based portion of crops (such as corn [the leaves, stalks, and cobs], orchard trimmings, and rice husks), perennial grasses, and animal waste. The description is the use of an agricultural product that required in potential market. About fuel pellet comprising determine a biomass material a particulate carbon-based material, and a silicate-based binder, that process in line with pellet biomass product.

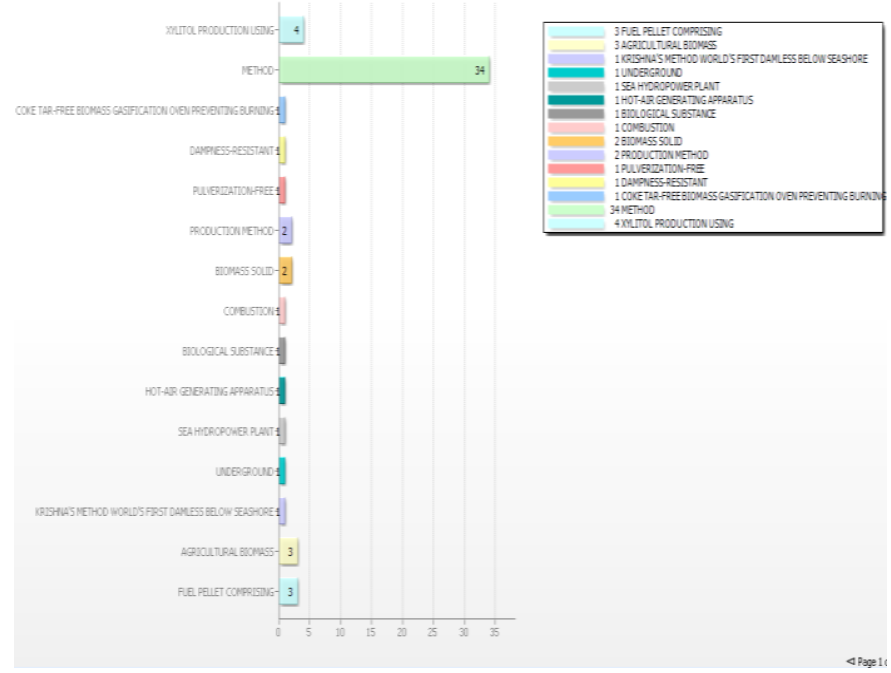

Fig. 4. Keyword Title from Pellet Biomass and EFB

From list of inventor (a person who is doing the work to produce a new thing for the first time from ideas and motivated by the work) that have done the research and development based on Pellet Biomass from empty fruit bunch in figure 5., shown that Ida Tamio from Faculty Science and Engineering Kindai University that concern in area of Renewable Energy, Micro Combustion Science, Scale Modeling Engineering, Coating/Drying Engineering (Method, Process of biomass, 11) and Nakanishi Akio from Graduate School of Science and Engineering Kinki University that concern in area of Environmental Material, Recycling Material, Wood material, Carbonized Material (Method, Process and Production of Biomass, 9) from Japan has significant impact for seeking energy substitution, and almost of them comes from Asia region. The explanation of all this is because Japan trying to develop a substitute source of energy derived from non fossil. They from universities comes that work as researcher that aware in seeking energy alternative and development of materials. Unfortunately there has been no researchers from Indonesia who registered his patents internationally. 


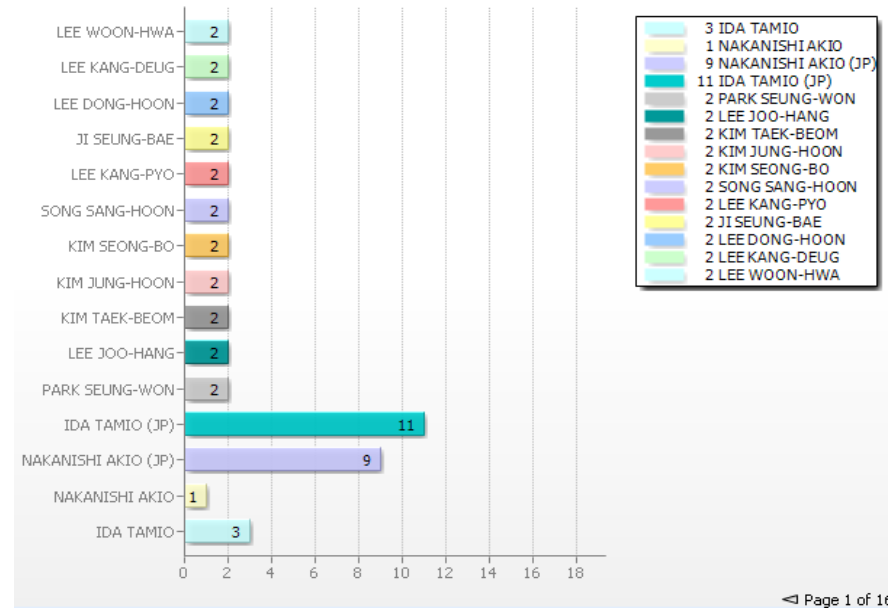

Fig. 5. Inventor of Patent on Pellet Biomass from EFB

After the inventor that produce technology, we also can find the number of applicant that used this patent implementation industry in Figure 6. Cheil Jedang Corporation with core subsidiary in charge of the food and bioengineering business unit achieved outstanding growth in food and food ingredients sector, as well as the bioengineering, bio-resource and pharmaceutical sector. (Food Industry, Korea, 9), Osaka Industrial Promotion Organization is to serve for industrial promotion in Osaka prefecture to contribute the sound growth and development of SMEs as well as other local industries, thereby form a robust economic region, improve the livelihood of those local residents and expand welfare services, with field business in Assistance for SMEs' business promotion and international business (Corporate Government, Japan, 4), Can Technologies Inc. is an Engineering Services company specialized in providing Information Technology, Control, Electrical and Mechanical Engineering Solutions to a variety of Industries, that provide a host of engineering and system integration services and have skilled and knowledgeable personnel with in depth domain experience and technical proficiency (Engineering Service, US, 4), Cargill Inc. businesses include risk management and financial solutions, animal nutrition, farm services, salt, energy, sweeteners and more especially in utilization on palm oil sector (Private Company in Food and Agricultural, US, 4) and Mitsubishi Heavy Industries Ltd provides construction through to after-sales services for various power generation facilities, including thermal power plants that achieve the world's highest generation efficiency and $\mathrm{CO}_{2}$ reduction levels, as well as nuclear, and wind power plants, contributing to stable power and better quality of life especially in developing renewable energy conservation (Manufacturing Energy and Environment, Japan, 4). Most of them located in Asian Region that concern of implementation process and impact energy preservation.

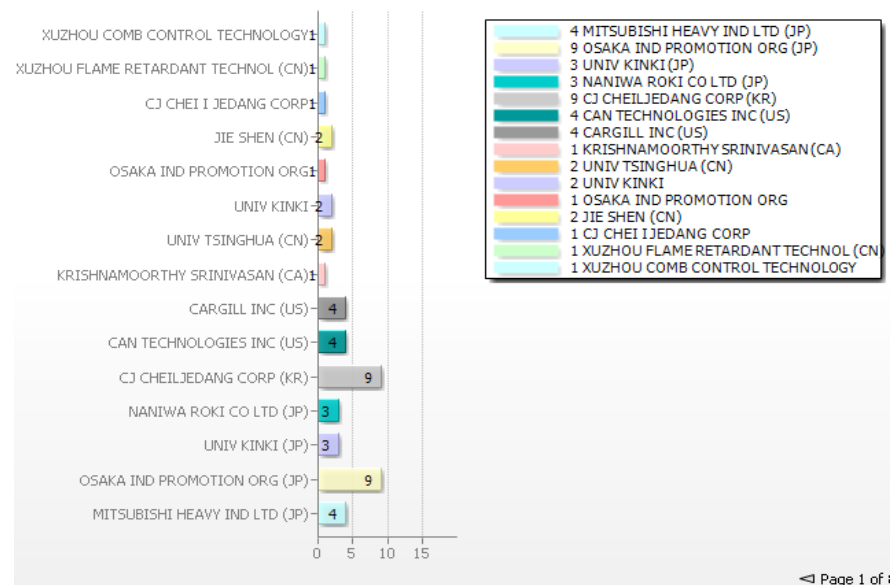

Fig. 6. Applicant on Patent Registration

Based on International Patent Classification (IPC) Full Class which provide hierarchical system of language independent symbols for the classification of patents and utility models according to the different areas of technology to which they pertain shown that in C10L5/44 area (Chemistry) C10 (Petroleum, Gas Or Coke Industries; Technical Gases Containing Carbon Monoxide; Fuels; Lubricants; Peat) L5/44 (Vegetable Substances) have 25 number of uses and C12P7/18 area (Chemistry) C12 (Biochemistry; Beer; Spirits; Wine; Vinegar; Microbiology; Enzymology; Mutation Or Genetic Engineering) P7/18 (Polyhydric Substances) with 7 uses implementation. And the last uses of patent in IPC Full Class C10B53/02 area (Chemistry) C10 (Petroleum, Gas Or Coke Industries; Technical Gases Containing Carbon Monoxide; Fuels; Lubricants; Peat) B53/02 (Cellulose Containing Material Substances) shown in Figure 7.

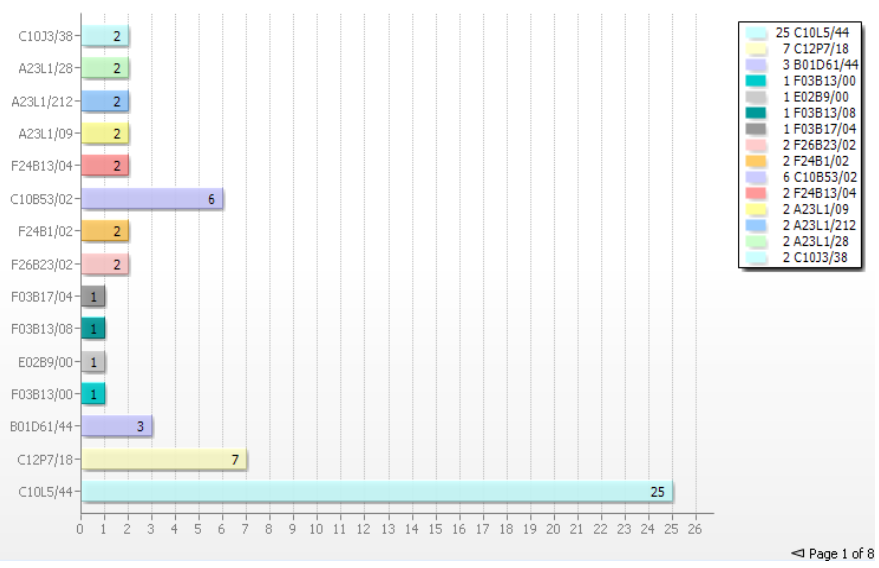

Fig. 7. IPC Full Class

If we search through World Intellectual Property Organization (WIPO) as global forum for intellectual property services, policy, information and cooperation that enables innovation and creativity, publish from entire patent registration in the world, we can define and analyze field of 
patent mostly used such as; Basic Material Chemistry category of patents primarily covers typical mass chemicals such as herbicides, fertilizers, paints, petroleum, gas, detergents (Chemistry) 41 fields, Biotechnology that concerns the application of cellular and molecular biology to make or modify products or processes. It includes scientific and industrial disciplines focused on understanding and manipulating living or biologically-active material at the molecular level, often involving DNA techniques and the analysis of genetic information (Chemistry) 22 fields and Environmental Technology that concern in Climate change mitigation technologies related to Buildings, Energy generation, transmission or distribution, Transportation, Capture, storage, sequestration or disposal of greenhouse gases, Environmental management, Water-related adaptation technologies (Chemistry) 14 fields and also Thermal Process and Apparatus that concern applications such as steam generation, combustion, heating, refrigeration, cooling or heat exchange (Mechanical Engineering) 14 fields like show in figure 8 .

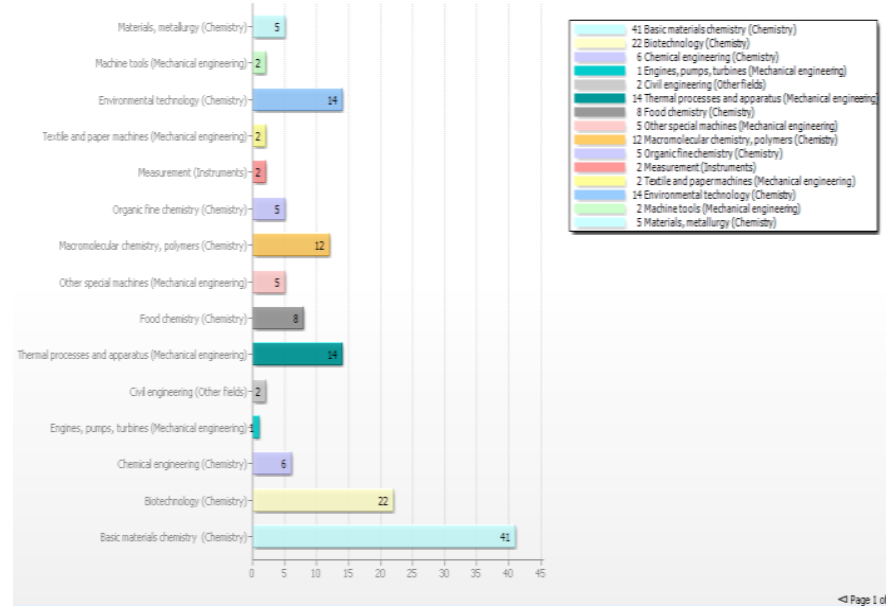

Fig. 8. WIPO Fields Data Substances

\section{CONCLUSION}

The investigation showed that trend in patent related to EFB biomass pellet is in the method. There are 2 possible reason why the patent trend is related to the method, which are : there are some difficulties that occurred in the current method, and the current method is less profitable for the stakeholder. This will require further investigation in the field and in the market.

Japan and China have been a major player for this industry, it showed in the number of applicant on the patent registration. So, this means that Indonesian research institutions are not interested in this field.

EFB pellet biomass patent investigation is just an early phase for further research that can give direction to innovation stakeholder. Analysis from this patent investigation define information can be used as a strategy for research and development of an organization. The presence of research strategy, expected to emerge results of research in the field of pellet biomass from empty fruit bunch to enhance development of renewable energy that are innovative and highly competitive.

After investigation found many usefulness on utilization of this product, particularly user from industry to promote market orientation through diversification of product production to fulfill the needs of user. From description analysis show that the uses of data patent searching still rarely use, this mean utilization still used base on personal interest and just become information for market review. For industry often used as derivative data for research and development in forecasting new variation of product to fulfill demand market competitiveness. Particular utilization in Indonesia, cannot be shown because still apply in domestic area and application in industry still zero also cannot be display in result of investigation data. Based on this experience, the following advantages of the proposed concept can be summarized: (1) immediate recommendations for $\mathrm{R} \& \mathrm{D}$ management and marketing to better align functional strategies; (2) improvement of inter-functional communication at the strategic level (as with Quality Function Deployment, a frequently used product design tool in which important product attributes valued by the customer are translated into product design characteristics which can be influenced by $\mathrm{R} \& \mathrm{D}$, at the project level); (3) reduction of discussion time about the foundations of the tool leading to a more focused discussion of content (strategic implications; productive discussion of "why" these portfolio positions have developed) due to the use of objective data, and (4) a high degree of face validity [12].

\section{ACKNOWLEDGMENT}

The author would like to thank to Head of Technology Incubation and Technology Transfer Division and Head of IPR Management at Center for Innovation, Indonesia Institute of Sciences that provide supports and information during data collection also permission to use of Matheo Patent XE Ver.10.2 software.

\section{REFERENCES}

[1] Sharma, P., Tripathi, R., C., Patent Database : A Methodology of Information Retrieval from PDF, International Journal of Database Management Systems, vol. 5, PP. 9 - 16, 2013.

[2] Ghaly, A.,E., Ergudenlet, A., Thermal Degradation of Cereal Straws in Air and Nitrogen. Journal of Applied Biochemistry and Biotechnology, Vol.27, No.1, PP. 111-126. 1991.

[3] Directorat General of New Renewable Energy and Energy Conservation, Statistic Book of New Renewable Energy and Energy Conservation Handbook. The Ministry of energy and Mineral Resources, 2015.

[4] Yanhong, L., Runhua, T., “ Text Mining Based Patent Analysis in Product Innovative Process “, Boston: Springer Verlag, 2007.

[5] Hendrix, T., " Implementation Policy of Acquisition Intangible Assets in Government Financial Statement ", Proceeding The $6^{\text {th }}$ IICIES, PP. 8994. 2014.

[6] Rockhoff, K., f., Competitor Technology Intelligence In German Companies. Industrial Market Management 1991;20:91-8. 
[7] Ernst, H., The Use Of Patent Data For Technological Forecasting: The Diffusion Of CNC Technology In The Machine Tool Industry. Small Business Economic 1997;9:361-81.

[8] National Energy Council, Outlook Energi Nasional Handbook, The Ministry Of Energy And Minral Resources, 2014.

[9] Akhtar, J., Kuang, S., K., Amin, N., S., Liquefaction Of Empty Palm Fruit Bunch (EPFB) In Alkaline Hot Compressed Water. Renewable Energy. 2010;35:1220-7.
[10] Hilman, H., Romadoni, A., The Management And Protection Of Intellectual Property Assets, A Guide For Researchers Biotechnology. The British Council, Bandung PP. 1-24. 2001.

[11] Jolly, V., K., Commercializing New Technologies, Harvard Business School Press. 1997.

[12] Ernst, H., Soll, J., H., An Integrated Portfolio Approach To Support Market Oriented R\&D Planning. International Journal Technology Management. PP. 540-561. 2003. 